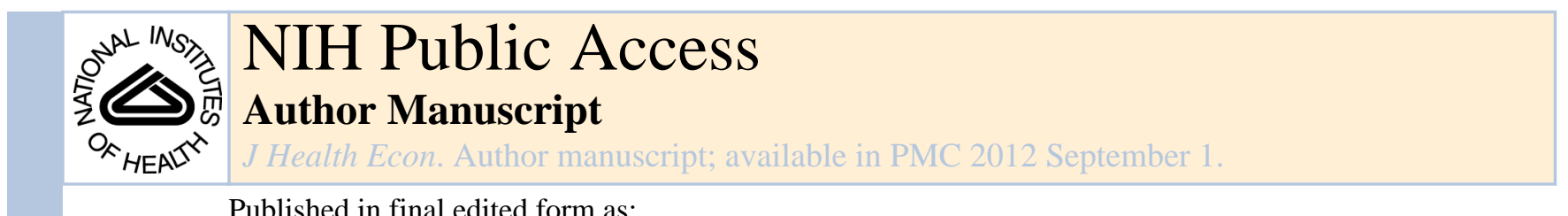

J Health Econ. 2011 September ; 30(5): 1094-1102. doi:10.1016/j.jhealeco.2011.07.003.

\title{
The Incidence of the Healthcare Costs of Smoking
}

\author{
Benjamin Cowan ${ }^{\dagger, \ddagger}$ and \\ School of Economic Sciences, Washington State University, Hulbert Hall 101, Pullman WA 99164 \\ USA \\ Benjamin Schwabł \\ Department of Agricultural and Applied Economics, University of Wisconsin-Madison, 427 Lorch \\ Street, Madison WI 53706 USA \\ Benjamin Cowan: ben.cowan@wsu.edu; Benjamin Schwab: bschwab@wisc.edu
}

\begin{abstract}
Smokers earn less than non-smokers, but much is still unknown about the source(s) of the smoker's wage gap. We build on the work of Bhattacharya and Bundorf (2009), who provide evidence that obese workers receive lower wages on account of their higher expected healthcare costs. Similarly, we find that smokers who hold employer-sponsored health insurance (ESI) receive significantly lower wages than their non-smoking peers, while smokers who are not insured through their employer endure no such wage penalty. Our results have two implications: first, the incidence of smokers' elevated medical costs appears to be borne by smokers themselves in the form of lower wages. Second, differences in healthcare costs between smokers and nonsmokers are a significant source of the smoker's wage gap.
\end{abstract}

\section{Keywords}

Smoking; Wages; Employer-sponsored health insurance; Compensating differential

\section{Introduction}

\begin{abstract}
Many studies document that smokers earn less than non-smokers even after controlling for a variety of individual characteristics. A large literature seeks to determine whether smoking has a causal effect on wages (see Levine et al., 1997; van Ours, 2004; Auld, 2005; and Grafova and Stafford, 2009 for some examples). While much attention has been paid to the question of causality, relatively few papers have examined specific mechanisms by which smoking may be related to wages. ${ }^{1}$ In this paper, we attempt to assess the empirical support for one explanation of the smoker's wage gap. In particular, we analyze whether smokers earn lower wages because they are more costly to their employers in terms of healthcare
\end{abstract}

\footnotetext{
(C) 2011 Elsevier B.V. All rights reserved.

†Corresponding author. Phone: (509) 335-2184. ben.cowan@wsu.edu.

*This research was supported by Award Number T32MH018029 from the National Institute Of Mental Health and the National Institute On Drug Abuse. The content is solely the responsibility of the authors and does not necessarily represent the official views of the National Institute Of Mental Health, the National Institute On Drug Abuse, or the National Institutes of Health. We are very grateful to Jay Bhattacharya and M. Kate Bundorf for sharing their data with us.

Publisher's Disclaimer: This is a PDF file of an unedited manuscript that has been accepted for publication. As a service to our customers we are providing this early version of the manuscript. The manuscript will undergo copyediting, typesetting, and review of the resulting proof before it is published in its final citable form. Please note that during the production process errors may be discovered which could affect the content, and all legal disclaimers that apply to the journal pertain.

${ }^{1}$ A notable exception is Viscusi and Hersch (2001), who show that smokers choose higher-risk jobs but receive less compensation for the risk they bear than do non-smokers.
} 
expenditures. By so doing, we also provide evidence on the extent to which smokers bear the incidence of their higher medical expenditures.

In the United States, more than $60 \%$ of the non-elderly population is covered by employersponsored health insurance (ESI) (Gruber, 2010). Employers who provide health insurance to their employees either pay premiums to an insurance firm or pay their employees' healthcare costs directly. For employers that purchase insurance, premiums are generally "experience-rated," meaning that past claims determine current premium rates (see Gruber, 1998). Thus, regardless of whether a firm offering ESI pools with other firms in an insurance market or acts as the insurer itself, a firm with employees who utilize more healthcare will, on average, incur higher costs. Since smoking leads to poorer health and higher health-care expenses, firms with a higher proportion of employees who smoke should have higher healthcare bills over time. ${ }^{2}$

Though employees' out-of-pocket contributions to ESI premiums could in theory reflect differences in observable risk factors such as smoking behavior, they are rarely adjusted for such differences in practice (Keenan et al., 2001). This may be due (at least in part) to nondiscrimination provisions under the Health Insurance Portability and Accountability Act (HIPAA) (see Mello and Rosenthal, 2008). ${ }^{3}$ Without the ability to charge higher-risk employees more for health insurance, employers should have an incentive to hire only workers with low observable health risks unless wages (or some other form of compensation) were adjusted for differences in expected healthcare costs. Bhattacharya and Bundorf (2009) use this logic to posit that obese workers with ESI earn less than their nonobese counterparts, but that no such wage gap exists among workers without ESI. Our paper builds on this work by using the National Longitudinal Survey of Youth (NLSY79) and the Medical Expenditure Panel Survey (MEPS) to examine the wage offset for smokers by health insurance status.

Similar to the finding in Bhattacharya and Bundorf (2009) for obese workers, our results indicate that smokers experience a significant wage gap relative to non-smokers in jobs with ESI but that no such penalty exists in jobs without ESI. Bhattacharya and Bundorf (2009) show that the obese worker's wage gap is concentrated among women; in contrast, our results indicate that both male and female smokers with ESI experience a wage penalty. This result is corroborated by evidence from the Medical Expenditure Panel Survey (MEPS) that medical expenses are higher for smokers among both sexes.

To attribute the differential wage gap by ESI status to healthcare costs associated with smoking, we rely on an identification strategy that is similar to the one used in Bhattacharya and Bundorf (2009). In particular, the validity of our results rests on the assumption that unobserved differences between smokers' and non-smokers' wages do not differ across firms based on their provision of health insurance. It is worth noting that unobserved productivity differences between smokers and non-smokers alone is not enough to threaten our strategy. Rather, such differences would have to be larger among workers with ESI than among workers without ESI to explain our results.

We provide three main pieces of evidence in support of our identification strategy. The first is that the wage gap for smokers with ESI is larger for older workers. This is consistent with

\footnotetext{
${ }^{2}$ On the relationship between smoking and medical costs, see Barendregt et al. (1997); Hodgson (1992); Manning et al. (1989); Miller et al. (1999); Pronk et al. (1999); and Warner et al. (1999).

${ }^{3}$ Mello and Rosenthal (2008) state on page 193, "The general rule under HIPAA is that no person can be denied group health insurance or charged more for coverage than other "similarly situated" persons because of health status, genetic history, evidence of insurability, disability, or claims experience. The phrase "similarly situated" refers to an employment-based classification, such as full-time or part-time, not a classification based on health factors."
} 
the empirical literature on the medical costs of smoking, which increase with age, presumably as the years spent smoking accumulate (Miller et al., 1999; Barendregt et al., 1997). Even if the productivity difference between smokers and non-smokers with ESI were larger than the one between smokers and non-smokers without ESI, it is not clear that the gap between the two differences would widen with age.

The second piece of evidence regarding identification is that our main result-that smokers only experience a wage penalty in jobs with ESI-holds when individual fixed effects are included in our model. In other words, exploiting only within-individual changes in smoking activity and/or health insurance yields a result that is similar to that of our baseline model (which is primarily based on cross-sectional variation in smoking status and ESI). The inclusion of controls for unobserved, time-invariant differences in workers makes it less likely that our results are due to a larger productivity difference between smokers and nonsmokers in jobs that provide health insurance than in jobs that do not. ${ }^{4}$

Following Bhattacharya and Bundorf (2009), the last piece of supporting evidence for our identification strategy is that we do not find a smoker's wage penalty for fringe benefits other than ESI. Since we only find a penalty associated with health insurance benefits, our results are not likely driven by unobserved differences between smokers and non-smokers that are correlated with the general availability of fringe benefits from one's employer.

Our results imply that the incidence of smokers' elevated medical costs falls on smokers themselves in the form of lower wages. In particular, our estimates of the differential wage offset for workers in jobs with ESI range from about $\$ 1.25$ to $\$ 1.85$ per hour, or from roughly $\$ 2,500$ to $\$ 3,700$ per year at a full-time job of 2,000 hours. ${ }^{5}$ We also estimate total medical costs by smoking status and find that smokers consume more healthcare resources than non-smokers. Our estimates of the difference in healthcare costs between smokers and non-smokers are economically and statistically significant for both sexes. Cost differences account for roughly 5 to $10 \%$ of the wage offset for both sexes. This appears to be a relatively small fraction of the wage gap, but there are some limitations to our healthcare cost analysis that may impede our ability to accurately estimate the cost difference associated with insuring smokers versus non-smokers. We discuss these issues in Section 4.4 .

In attempting to assess the financial burden that smokers impose on society, both Manning et al. (1989) and Viscusi (2002) count smokers' elevated medical costs as the largest single source of the external costs of smoking (due, at least in part, to the presumed effect these costs have on non-smokers' health insurance premiums). Our results indicate that even though smokers may not pay higher premiums per se, the added medical costs of smokers with ESI are fully offset by the difference in their wages. ${ }^{6}$ Because both Manning et al. (1989) and Viscusi (2002) estimate that taxes on cigarettes exceed the average external costs of smoking, our findings imply that the extent to which smokers subsidize non-smokers may be larger than previously thought.

\footnotetext{
${ }^{4}$ Bhattacharya and Bundorf (2009) do not provide evidence on whether the effect of obesity on wages increases with age. They also indicate that when they include individual fixed effects in their model, there is no evidence of a wage offset for obese workers with ESI. They attribute this result to a lack of statistical power.

${ }_{5}$ All monetary figures are denoted in 2002 dollars (\$2002) throughout the paper.

6 Of course, smokers who are not insured through their employer may impose external costs on society if they receive health insurance through the government or receive care at a free or subsidized rate.
} 


\section{Empirical Framework}

The conceptual model on which our empirical analysis is based is contained in Bhattacharya and Bundorf (2009). We assume a competitive spot market for labor such that in jobs with no fringe benefits, the wages of worker $i, w_{i}$, are equal to the worker's marginal revenue product, $M R P_{i}$. In jobs that provide health insurance, if the incidence of a worker's healthcare costs is borne at the individual level, and if premiums are actuarially fair, then wages will be equal to marginal revenue product minus expected healthcare costs, $M R P_{i}-$ $E\left[m_{i}\right]$.

The alternative to individual-specific incidence is that all workers in a firm pool their healthcare costs. If this is the case, an arbitrage opportunity exists for firms who hire only "healthy" workers. In addition, such pooling would likely be easier in large firms, where the marginal employee's healthcare expenses have a small effect on premiums. As a result, we would expect that under group incidence, the smoker's penalty in small firms with ESI would be larger than the penalty in large firms with ESI. As discussed in Section 4.2, we find that insured smokers experience a wage penalty in both small and large firms.

Throughout our paper, we estimate models of the following form:

$$
w_{i}=\alpha+X_{i} \beta+\delta * H I_{i}+\gamma * S_{i}+\lambda * H I_{i} * S_{i}+\varepsilon_{i},
$$

where $w_{i}$ represents the hourly wage of worker $i, H I_{i}$ indicates whether worker $i$ receives health insurance through her employer, $S_{i}$ indicates whether worker $i$ smokes, $X_{i}$ represents other observable characteristics that affect wages, and $\varepsilon_{i}$ is the regression error. The difference-in-difference parameter is given by $\lambda$, which represents the differential wage offset for smokers with ESI compared to smokers without ESI.

Smoking status $S_{i}$ is likely to be correlated with unobserved characteristics that affect wages in $\varepsilon_{i}$. Our key identifying assumption is that any unobserved differences in wages between smokers and non-smokers are not correlated with ESI status. If this the case, $\lambda$ represents the wage penalty due to smokers' higher healthcare costs. We provide evidence on the plausibility of this assumption in Section 4.2.

\section{Data}

We use the National Longitudinal Survey of Youth, 1979 cohort (NLSY79) for our main analysis. The NLSY79 is a nationally representative sample of youths who were between 14 and 22 years old in 1979. The survey was conducted annually until 1994, after which it has been conducted biennially. We use data from 1989 through 2002 excluding 1991 in our analysis. We focus on these years because prior to 1989, health insurance status was not reported, nor was it reported in 1991. The individuals in our sample range from 25-45 years old.

We follow Bhattacharya and Bundorf (2009) in restricting our analysis to full-time workers in private and non-profit firms who either have employer-sponsored insurance from their current employer or are uninsured. We also drop those person-year observations in which women are pregnant, owing to the fact that their smoking status may change temporarily during the pregnancy. Data on smoking behavior are available in only three years in our sample frame: 1992, 1994, and 1998. For years prior to 1994, we define smoking status to be equal to one's status in 1992; for 1994 and 1996, we define smoking status to be equal to one's status in 1994; finally, for 1998 and subsequent years, smoking status is given by one's status in 1998. Due to the ad-hoc nature of our definition of smoking status in years 
for which we have no smoking data, we tried using several alternative definitions of smoking status in our empirical models. ${ }^{7}$ Results presented throughout the paper are robust to changes in the definition of smoking status.

We define an individual to be a smoker at a given point in time if he/she reports being a current daily smoker. After excluding observations from the sample based on missing smoking information or other key variables, we are left with 27,380 person-year observations. In our baseline model, we include the following set of covariates: the survey year, gender, race (white, black, and other), an indicator of whether there are any children in the household and its interaction with gender, marital status (never married, married with spouse present, and other), age, age squared, education level measured by highest grade completed (0-8 years, 9-12 years, and 13 or more years), AFQT score (0-24th percentile, 25th-50th percentile, 51st-75th percentile, 76th-100th percentile), job tenure (less than 48 weeks, 48-143 weeks, 144-287 weeks, and 288 or more weeks), location of residence (urban or rural), number of employees at workplace (fewer than 10 people, 10-24 people, 25-49 people, 50-999 people, and 1000 or more people), industry category, and occupation category. ${ }^{8}$ Summary statistics by group (all individuals, never-smokers, always-smokers, quitters, and starters) are presented in Table 1.

In addition to the NLSY79, we use the 2000-2005 waves of the Medical Expenditure Panel Survey (MEPS) for certain supplementary analyses in the paper. MEPS collects nationally representative data on healthcare spending and health insurance coverage for the noninstitutionalized population in the U.S. The recorded expenditures include both respondents' out-of-pocket costs and expenditures paid on their behalf by third parties (such as insurance companies). In addition, MEPS contains information on wages, smoking status, and many (but not all) of the controls that are available in NLSY79. 9 The primary advantage of MEPS is that it contains data on respondents' healthcare expenditures (whereas the NLSY79 does not). This allows us to compare medical expenditures of smokers and non-smokers in Section 4.4. Summary statistics on MEPS samples used in the paper are provided in Appendix Table 1.

\section{Empirical Results}

\subsection{Baseline model}

Our main results on the smoker's wage offset by insurance status using the NLSY79 are contained in Table 2. Because we use repeated observations on NLSY79 respondents, we account for intra-person correlation in error terms by clustering standard errors at the individual level. The first column of Table 2 shows results from an ordinary least squares regression of hourly wages on an indicator for daily smoking ("Smoker"), an indicator for health insurance through one's own employer ("ESI"), the interaction between the two ("Smoker * ESI"), and all control variables discussed in Section 3.

\footnotetext{
${ }^{7}$ For example, we tried assigning smoking status based on responses in 1992 only. We also tried a definition similar to that outlined in the text but assigned smoking status in 1993 to one's status in 1994 and smoking status in 1996 to one's status in 1998. Lastly, we ran our models using only those years for which we have smoking data $(1992,1994$, and 1998). Results with this restricted sample were similar to those presented in the paper; however, they were less precisely estimated in a few cases (likely on account of the large reductions in sample sizes).

${ }^{8}$ This is the same set of covariates used in Bhattacharya and Bundorf (2009). Industry categories include agriculture; forestry and fisheries; mining; construction; manufacturing; transportation, communications, and other public utilities; wholesale trade; retail trade; finance, insurance and real estate; business and repair services; personal services; entertainment and recreation services; professional and related services; and public administration. Occupation categories include managerial and professional specialty; technical and sales; administrative support; service; farming, forestry, and fishing; precision, production, craft, and repair; operators, fabricators, and laborers; and armed forces.

${ }^{9}$ AFQT score is a notable exception. In addition, due to the short (2-year) panel available in MEPS, we do not include individual fixed effects in any of these regressions.
} 
As seen in Column 1 of Table 2, smokers with ESI earn \$1.72 less than non-smokers with ESI (the coefficient on "Smoker" plus the coefficient on "Smoker*ESI"). Smokers without ESI earn a statistically insignificant $\$ 0.12$ more than non-smokers; thus, the difference-indifference estimate is $-\$ 1.84$ (the coefficient on "Smoker $* E S F^{\prime}$ ). ${ }^{10}$ This represents roughly a $10 \%$ reduction in hourly wages at the mean. 11,12

In Columns 2 and 3 of Table 2, we show the results of the baseline model for men and women separately. The full sample is composed of 16,778 male person-year observations and 10,602 female person-year observations. The effects of daily smoking, ESI coverage, and the interaction of the two are similar across gender. In particular, the difference-indifference estimate is $-\$ 1.88$ for men and $-\$ 1.55$ for women, and both results are significant at the $1 \%$ level. This result stands in contrast to Bhattacharya and Bundorf (2009), who find a significant wage penalty for obesity among female workers with ESI (relative to no penalty for female workers without ESI) but no such differential for men. Using data from MEPS, we show in Section 4.4 that smokers' healthcare costs are indeed greater than non-smokers' costs among both sexes.

To examine the robustness of our NLSY79 results, we run our baseline model using MEPS data. MEPS not only measures the take-up of insurance (as in the NLSY79) but also the offer of insurance by firms to workers. This allows us to examine whether the smoker's wage offset is different depending on whether the "insured" group is workers who hold ESI or workers whose firms offer ESI. ${ }^{13}$ We begin by defining individuals as possessing ESI if they are continually insured by their employer throughout the year. We then use a less restrictive definition of coverage: having held insurance at any point during the year. The last and least restrictive definition is based on the offer rather than the take-up of insurance. In this case, we define individuals as being covered by ESI if they were offered insurance by their employer at any point throughout the year. In each of these three cases, we compare the group covered by ESI with those who are continually uninsured during the year. ${ }^{14}$

The difference-in-difference ("Smoker *EST") coefficients from the alternative wage-offset regressions using MEPS are contained in Table 3. ${ }^{15}$ These estimates are stable across insurance definition and are slightly smaller in absolute value than their counterparts in the NLSY79 baseline model (Table 2, Columns 1-3). For example, the differential wage offset for all continuously insured smokers is about $\$ 1.39$ per hour. Point estimates for women are generally smaller in absolute value than they are for men (as they are in the NLSY79), but

\footnotetext{
${ }^{10} \mathrm{As}$ is the case in Bhattacharya and Bundorf (2009), we find a positive and significant relationship between the presence of health insurance and wages. Detecting the presence of a compensating differential is made difficult by the presence of unobserved worker characteristics that are correlated with compensation both in the form of wages and fringe benefits (Levy and Feldman, 2001). It is important to note that such unobserved heterogeneity alone is not a threat to our strategy. Rather, the validity of our result depends on whether unobserved productivity differences between smokers and non-smokers depend on whether they receive health insurance through their employer, controlling for other worker and employer characteristics.

${ }^{11}$ We also estimated these regressions using log wages, though we consider wages in levels to be the more appropriate specification of the dependent variable. Similar to Bhattacharya and Bundorf (2009), we argue that smoking-related wage offsets should be independent of a worker's wage rather than proportional to it. That is, if smoking costs are borne by workers with ESI, the offset should not vary depending on whether the cost is low or high in proportion to an individual's wage. Nevertheless, when we use log wages as the dependent variable, we find that smokers with ESI earn $6.3 \%$ lower wages.

12 In results that are available upon request, we show that when we examine the smoker's and obese worker's wage offsets simultaneously, the coefficient on "Smoker *ESI" is $-\$ 1.63$ (standard error of 0.51) and the coefficient on "Smoker*Obese *ESI" is $\$ 1.38$ (standard error of 0.78 ). Thus, there is some evidence that obese smokers endure a larger penalty in jobs with ESI than do nonobese smokers. In addition, the coefficient on "Obese *ESI" (-\$0.53) is no longer significant (standard error of 0.53) in this

${ }^{13}$ Even if smokers do not accept the offer of health insurance from their employer, they may experience a wage penalty nonetheless if they can take up the insurance at any time.

${ }^{14}$ We find very similar wage-offset effects for smokers if we include those individuals who obtain insurance through means other than their employer with the uninsured in these regressions.

${ }^{15}$ We follow Bhattacharya and Bundorf (2009) in restricting our sample to closely match that of the NLSY79 by including 18-50 year-old workers who are continuously employed during the year, not self-employed, and work at least 35 hours per week on average.
} 
differences by sex are never significant at conventional levels. Even though this analysis suggests a somewhat smaller wage offset than the one yielded by the NLSY79 data, the evidence provided by MEPS affirms the NLSY79 result that both male and female smokers experience a significant wage penalty when they hold or are offered employer-sponsored health insurance.

\subsection{Results with individual fixed effects, by age, and by firm size}

In this section, we again utilize the NLSY79 to check the robustness of our baseline results contained in Section 4.1. Column 4 of Table 2 shows the results of a model that includes individual fixed effects and the subset of time-varying right-hand side variables from the baseline model (i.e. this model excludes sex, race, and AFQT score). Of the 6,140 individuals in the NLSY79 sample (constituting 27,380 person-year observations), 5,173 provide data in multiple years of the survey (on average, we observe individuals 4.5 times over the course of the panel). Among these, over $36 \%$ have at least one observation in which they are currently receiving ESI and one in which they are uninsured. Furthermore, over $12 \%$ of those with multiple observations have at least one in which they smoke daily and one in which they do not smoke daily. These two sources of variation provide identification of the coefficients of interest in the fixed-effect model. ${ }^{16}$

As in the baseline model, the effect of daily smoking on wages for workers without ESI in the fixed-effect model is positive but not significantly different from zero. The difference-indifference estimate, however, is $-\$ 1.25$, which is significant at the $5 \%$ level. Columns 5 and 6 of Table 2 display the fixed-effect results for men and women, respectively. Though the difference-in-difference coefficient for women of $-\$ 0.65$ is somewhat smaller than it is in the OLS case, it is only marginally insignificant (p-value of 0.12 ) and still not statistically distinguishable from the effect for men. Broadly speaking, the fixed-effects model, which utilizes only within-individual variation in smoking and insurance status, confirms the results of the OLS model: smokers in jobs with ESI bear a unique wage burden relative to their non-smoking peers.

We now turn to examining the effect of smoking on wages by age. Because the expected medical costs of smoking rise as past consumption of cigarettes rises (Miller et al., 1999; Barendregt et al., 1997), we expect the differential wage gap for smokers with ESI to increase with age. In Columns 1 and 2 of Table 4, we show the results of the baseline OLS model for younger (less than 40 years old) and older (age 40 and higher) workers separately.

The results in the table indicate that the smoker's wage penalty among young workers with ESI $(-\$ 1.52)$ is economically and statistically significant, but it is less than half of the wage gap of insured smokers age 40 and over $(-\$ 3.39)$. These two coefficients are significantly different at the 5\% level. In addition, both younger and older smokers without ESI receive no less pay than their non-smoking colleagues. Thus, the relative wage offset for smokers with ESI follows a similar age pattern to that documented in the medical literature for smokers' relative medical risks. ${ }^{17}$ Furthermore, these results are consistent with our cost analysis using MEPS data, which we discuss in Section 4.4.

We have demonstrated that smokers with ESI experience a wage penalty relative to nonsmokers and uninsured smokers, which is consistent with the incidence of smokers' medical costs being borne at the individual level. However, it is possible that these costs are pooled

\footnotetext{
16 In Appendix Table 2, we provide a matrix of year-to-year transitions in smoking and ESI status for individuals in our sample. ${ }^{17}$ We found no evidence that the smoker's wage penalty in jobs with ESI increases with age prior to age 40 . Our cost analysis was broadly consistent with this finding: the cost difference between smokers and non-smokers is similar among 20-30 year-olds and 3040 year-olds but rises sharply for $40-50$ year-olds.
} 
at the firm level in large firms but that smokers in smaller firms, where pooling is more difficult, bear a disproportionate share of their own costs. For this reason, we consider the smoker's wage penalty in small firms versus large firms in Columns 3 and 4 of Table 4 . The results indicate that the insured smoker's wage gap is present among both small (less than 50 employees) and large employers (50 or more employees). ${ }^{18}$ Though the point estimate is somewhat larger among small firms ( $-\$ 2.23$ versus $-\$ 1.27$ in large firms), these estimates are not statistically different from one another. Overall, our results imply that individual smokers bear the cost of their increased medical risk through lower wages.

\subsection{Other fringe benefits}

In this section of the paper, we test whether smokers whose jobs provide fringe benefits other than ESI endure a larger wage penalty than smokers in jobs with no such benefits. The key to this falsification exercise is that there are many benefits-unlike health insurance-that cost roughly the same amount to provide to smokers and non-smokers. ${ }^{19}$ If a larger wage offset for smokers relative to non-smokers were observed in jobs with these other kinds of fringe benefits, it would call into question whether our main results on ESI are in fact due to differences in expected healthcare costs. Rather, it would suggest that unobserved differences between smokers and non-smokers are not uniform across jobs based on their likelihood of providing a variety of fringe benefits (including ESI).

The alternative fringe benefits available in the NLSY79 include separate indicators for whether a respondent's employer provides flexible hours, child care, vocational training, profit-sharing, retirement benefits, maternity leave, dental insurance, and life insurance. ${ }^{20}$ We perform separate regressions in which each of these benefits (and its interaction with "Smoker") is in turn added to our baseline model. ${ }^{21}$ The results of these eight regressions are contained in Table 5. In this table, we only report the effect of "Smoker ${ }^{*} F B$ " in each regression, where " $F B$ " represents the fringe benefit under consideration. ${ }^{22}$

The difference-in-difference coefficients reported in Table 5 are not statistically significant in the cases of flexible hours, child care, vocational training, profit-sharing, maternity leave, dental insurance, and life insurance. The coefficient on "Smoker *Retirement" is negative and marginally significant at the $10 \%$ level. Since the point estimate for one out of the eight benefits $(12.5 \%)$ is significant at the $10 \%$ level, this result could simply be due to the probability of a Type I error being $10 \%$. Furthermore, the presence of retirement benefits may not only be correlated with the provision of health insurance but also the generosity of insurance conditional on its provision. Thus, it remains possible that their effect on the wage penalty for smokers is overstated; that is, their effect is masking part of the effect of health insurance on the wage gap in these regressions. To test this possibility, we re-examined the effect of these benefits on the smoker's wage gap for only those workers without ESI. ${ }^{23}$ Among this group, we find no evidence of a differential wage offset for smokers in jobs with

\footnotetext{
${ }^{18}$ We also tried more restrictive definitions of a large firm (e.g. 1000 or more employees) and found similar results.

${ }^{19}$ This exercise is very similar to one performed in Bhattacharya and Bundorf (2009). We discuss differences between our analysis and their analysis below.

${ }^{20}$ Even though smokers have a higher risk of mortality, life insurance premiums are often adjusted for smoking status, unlike employer-sponsored health insurance premiums.

${ }^{21}$ Here we depart from Bhattacharya and Bundorf (2009), who do not condition on health insurance in their alternative fringe benefit regressions. We believe this is overly restrictive give the high degree of correlation between an employer's provision of ESI and its provision of other kinds of fringe benefits. Failing to condition on ESI coverage when examining the effect of some other fringe benefit on the smoker's wage penalty may confound the effects of ESI and the other fringe benefit on the wage penalty.

${ }^{22} \mathrm{We}$ also tried regressing wages on the full set of fringe benefits (including ESI) and the full set of interactions between each benefit and daily smoking. In this model, the coefficient on "Smoker *ESI" was $-\$ 1.49$ with a standard error of 0.45 . No other difference-indifference coefficient with respect to any other fringe benefit was significant at the $10 \%$ level. Furthermore, the null hypothesis that difference-in-difference coefficients for all fringe benefits other than ESI are jointly equal to zero cannot be rejected at the $10 \%$ level. ${ }^{23}$ Among workers without ESI, over $22 \%$ reported that their employer offered retirement benefits.
} 
retirement benefits. ${ }^{24}$ Overall, these results provide evidence that the presence of employersponsored health insurance coverage leads to a wage gap for smokers due to higher expected healthcare costs rather than differences in unobserved worker productivity.

\subsection{Medical expenditures}

In Sections 4.2 and 4.3, we use a series of robustness checks and falsification exercises to scrutinize the claim that the wage penalty for smokers derives from their elevated health insurance costs to employers. In this section of the paper, we directly examine whether smokers have higher medical costs than non-smokers. To do so, we use expenditure data from the 2000-2005 waves of the Medical Expenditure Panel Survey (MEPS). ${ }^{25}$

MEPS respondents are drawn from a sample of the previous year's wave of another survey: the National Health Interview Survey (NHIS). Approximately 90 percent of MEPS observations can be successfully linked to the NHIS, with the remainder consisting of newborns and other new members of the household. Within NHIS, one adult household member is randomly selected to answer detailed questions on past and current smoking behavior. We restrict the cost analysis that follows, which combines expenditure data from MEPS and smoking data from NHIS, to this subset of individuals. ${ }^{26}$

We have posited that smokers endure a wage penalty when they receive health insurance through their employer because they have, in expectation, higher healthcare expenditures. We would like to test this claim by comparing the expected costs of smokers and nonsmokers. One difficulty, however, is that the expected healthcare costs of current smokers are not accurately represented by the contemporaneous costs of the same group. The reason is that smokers (and non-smokers) may change their smoking status at any time, and smokers may be induced to quit smoking as a result of negative health shocks, which are clearly related to medical expenditures (see Miller et al., 1999). As a result, comparing the expenditures of current smokers to all other individuals likely understates the difference in costs an employer providing insurance expects to incur from an employee who smokes versus one who does not.

Consequently, rather than compare the medical costs of current smokers and non-smokers, we examine the costs of ever-smokers versus never-smokers. Ever-smokers are made up of those who are currently smoking at least one cigarette per day (current smokers) and those who do not currently smoke but have smoked at least 100 cigarettes in their lifetime (former smokers). ${ }^{27}$ Unadjusted mean annual medical expenditures for these two groups by sex and age category are presented in Table $6 .{ }^{28}$ As seen in the table, 18-64 year-old female (male) ever-smokers spend $\$ 551$ (\$628) more on healthcare per year than their never-smoker peers.

\footnotetext{
${ }^{24}$ For workers who do not have ESI, the difference-in-difference estimate is $-\$ 0.28$ (standard error of 0.50 ) for the interaction of smoking status and retirement benefits. Meanwhile, for workers who do not have retirement benefits, the difference-in-difference estimate is $-\$ 1.36$ (standard error of 0.68 ) for the interaction of smoking status and ESI.

${ }^{25}$ Here again we follow Bhattacharya and Bundorf (2009), who use MEPS for the similar purpose of examining healthcare costs by obesity status.

${ }^{26}$ Restricting the analysis to the linked sample is necessary due to the absence of information on past smoking behavior in MEPS alone. In the text, we explain why having information on past smoking is important in this context. Summary statistics on the linked sample are provided in Appendix Table 1.

${ }^{27}$ We also ran the NLSY79 wage offset analysis for ever-smokers (instead of current smokers) and for former smokers and current smokers separately. The wage offset for current smokers (\$1.84) is larger than it is for ever-smokers $(\$ 1.57)$, but the latter is still significant at the $1 \%$ level. The reason is that when current and former smokers are included separately in the regression, the wage offset is concentrated among current smokers. It is well documented that former smokers have higher costs than never-smokers (see, for example, Pronk et al., 1999), so we believe that former smokers avoid a wage penalty because their risk status is more difficult for employers to observe. This is a topic for future study.

${ }^{28}$ We also examined adjusted cost differences after controlling for a variety of characteristics, including race, education, marital status, region, year, and obesity status. The results are very similar to the unadjusted results presented in the paper, so we suppress them here.
} 
These differences shrink for 20-50 year-olds (the age category most similar to the NLSY79 sample), and they shrink again when only 20-50 year-olds with private insurance are considered. Nevertheless, even among this latter group, annual costs for ever-smokers are $\$ 251$ higher for females and \$281 higher for males. ${ }^{29}$ These estimates are each independently significantly different from zero at the $10 \%$ level, and they are also not significantly different from each other at conventional levels.

Furthermore, Table 6 shows that cost differences between smokers and non-smokers clearly increase with age. For individuals age 40 and younger, the difference in costs is $\$ 115$ for females and \$208 for males. For those above age 40, cost differences increase to $\$ 623$ and $\$ 591$ for women and men, respectively. The divergence in costs between smokers and nonsmokers with age is consistent with the results in Table 4, where we show that the wage offset for smokers with ESI is substantially larger for older workers.

\section{Conclusions}

In this paper, we examine the role that healthcare costs play in the well-documented smoker's wage penalty. Following the argument of a similar study on obesity by Bhattacharya and Bundorf (2009), we hypothesize that if differences in healthcare costs between smokers and non-smokers explain the penalty, then the penalty should exist only among workers who receive health insurance through their employer. We find a significant wage penalty for smokers with employer-sponsored insurance (ESI) but no penalty for smokers without ESI. Our results are robust to the inclusion of individual fixed effects, imply that older smokers with ESI endure a larger wage penalty, and suggest that after conditioning on ESI, wage differentials for workers in jobs with fringe benefits other than ESI are not correlated with smoking status.

We also show that smokers have higher annual medical expenditures than non-smokers. Our best estimates of the wage offset imply that the percentage of the annual smoker's penalty (based on a 2,000 hour work year) that is accounted for by cost differences is about 5-10\% for both sexes.

As a result of our finding that medical expenditures do not account for the entire wage gap for smokers with ESI, we cannot rule out the possibility that factors other than actual cost differences contribute to the gap. For example, it is possible that employers who offer ESI systematically overestimate the cost of insuring smokers. Other explanations are offered by Bhattacharya and Bundorf (2009), who similarly find that a small fraction of the obese female's wage gap is explained by observed differences in costs. These explanations include insurance loading (such that insurance costs are greater than those that would be implied by actuarially fair premiums) and statistical noise.

The body of evidence in this paper casts doubt on the notion that the correlation between the smoker's wage gap and employer-sponsored insurance is the result of productivity differences between smokers and non-smokers. Whether better measures of the relative cost of insuring smokers can account for a larger fraction of the wage offset, or if alternative explanations are needed to explain the difference between smokers' costs and their wage gap, is a subject for future research.

What seems clear from our analysis is that smokers bear the full incidence of their elevated healthcare costs through lower wages. This is relevant for public policy given that Manning et al. (1989) and Viscusi (2002) have found that at current tax rates on cigarettes, smokers

\footnotetext{
${ }^{29}$ Our results are roughly similar to those obtained in Pronk et al. (1999).
} 
subsidize non-smokers overall. Since these studies presume that non-smokers subsidize the health insurance premiums of smokers, our results imply that the evidence that smokers "pay their way" is stronger than previously thought.

\section{References}

Auld MC. Smoking, Drinking, and Income. Journal of Human Resources. 2005; 40:505-518. rX: 848720 (on Jul 23, 2009).

Barendregt J, Bonneux L, vanderMaas P. The health care costs of smoking. New England Journal of Medicine. 1997; 337:1052-1057. [PubMed: 9321534]

Bhattacharya J, Bundorf MK. The Incidence of the Healthcare Costs of Obesity. Journal of Health Economics. 2009; 28:649-658. rX: 850816 (on Apr 14, 2010). [PubMed: 19433210]

Grafova IB, Stafford FP. The Wage Effects of Personal Smoking History. Industrial and Labor Relations Review. 2009; 62:381-393. rX: 850816 (on Jun 10, 2010).

Gruber, J. NBER Working Papers. Vol. 6762. SO: National Bureau of Economic Research, Inc; 1998. Health Insurance and the Labor Market; p. 1998RX: 850816 (on Jun 10, 2010)

Gruber, J. NBER Working Papers. Vol. 15766. SO: National Bureau of Economic Research, Inc; 2010. The Tax Exclusion for Employer-Sponsored Health Insurance; p. 2010RX: 850816 (on Jun 10, 2010)

Hodgson TA. Cigarette-Smoking and Lifetime Medical Expenditures. Milbank Quarterly. 1992; 70:81-125. [PubMed: 1588892]

Keenan PS, Buntin MJB, McGuire TG, Newhouse JP. The Prevalence of Formal Risk Adjustment in Health Plan Purchasing. Inquiry. 2001; 38:245-259. rX: 850816 (on Jun 10, 2010). [PubMed: 11761352]

Levine PB, Gustafson TA, Velenchik AD. More Bad News for Smokers? The Effects of Cigarette Smoking on Wages. Industrial and Labor Relations Review. 1997; 50:493-509. rX: 848720 (on Jul 23, 2009).

Levy H, Feldman R. Does the Incidence of Group Health Insurance Fall on Individual Workers? International Journal of Health Care Finance and Economics. 2001; 1:227-247. rX: 850816 (on Sep 25, 2010). [PubMed: 14625927]

Manning WG, Keeler EB, Newhouse JP, Sloss EM, Wasserman J. The Taxes of Sin - Do Smokers and Drinkers Pay Their Way? JAMA-Journal of the American Medical Association. 1989; 261:16041609.

Mello MM, Rosenthal MB. Wellness programs and lifestyle discrimination - The legal limits. New England Journal of Medicine. 2008; 359:192-199. [PubMed: 18614787]

Miller VP, Ernst C, Collin F. Smoking-attributable medical care costs in the USA. Social Science and Medicine. 1999; 48:375-391. [PubMed: 10077285]

Pronk N, Goodman M, O'Connor P, Martinson B. Relationship between modifiable health risks and short-term health care charges. JAMA-Journal of the American Medical Association. 1999; 282:2235-2239.

van Ours JC. A Pint a Day Raises a Man's Pay; but Smoking Blows That Gain Away. Journal of Health Economics. 2004; 23:863-886. [PubMed: 15353183]

Viscusi, WK. Smoke-filled rooms: A postmortem on the tobacco deal. Chicago and London: University of Chicago Press; 2002. rX: 850816 (on Sep 16, 2010)

Viscusi WK, Hersch J. Cigarette Smokers as Job Risk Takers. Review of Economics and Statistics. 2001; 83:269-280. rX: 850816 (on Sep 14, 2010).

Warner KE, Hodgson TA, Carroll CE. Medical costs of smoking in the United States: estimates, their validity, and their-implications. Tobacco Control. 1999; 8:290-300. [PubMed: 10599574] 


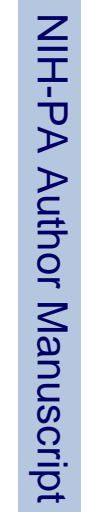

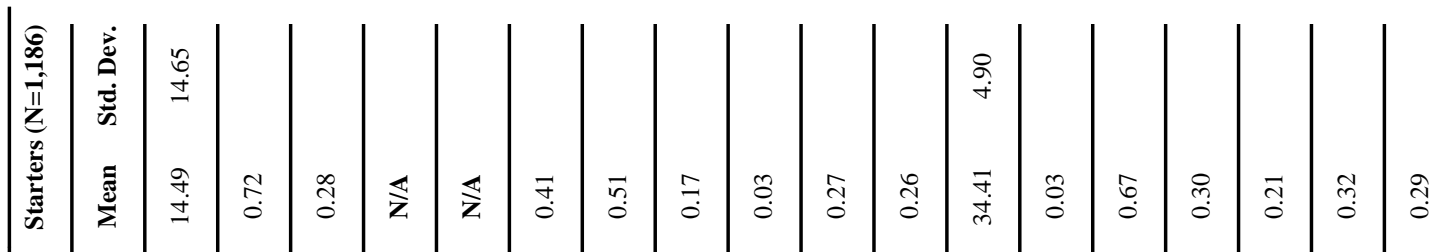

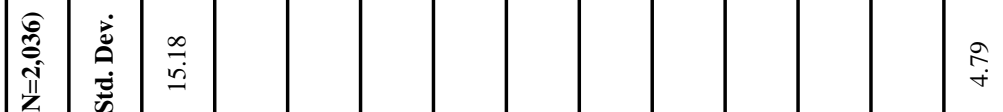

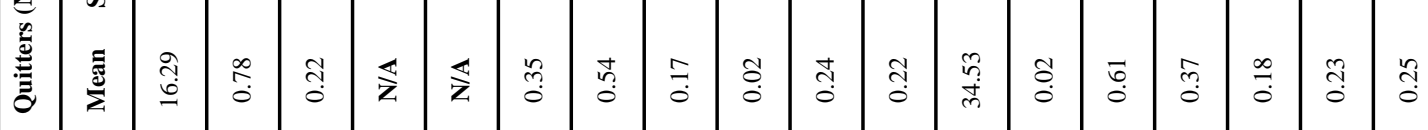

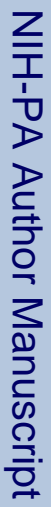

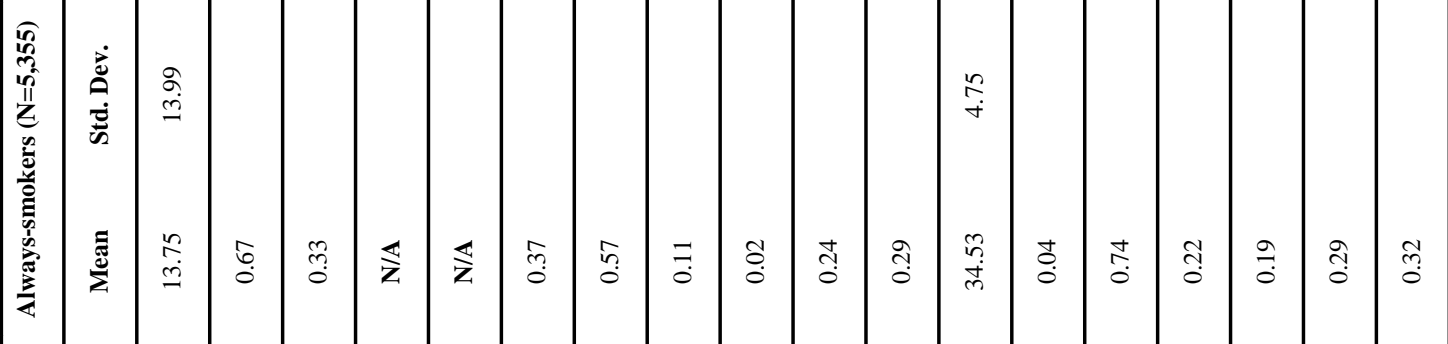

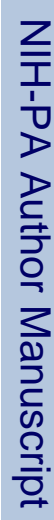

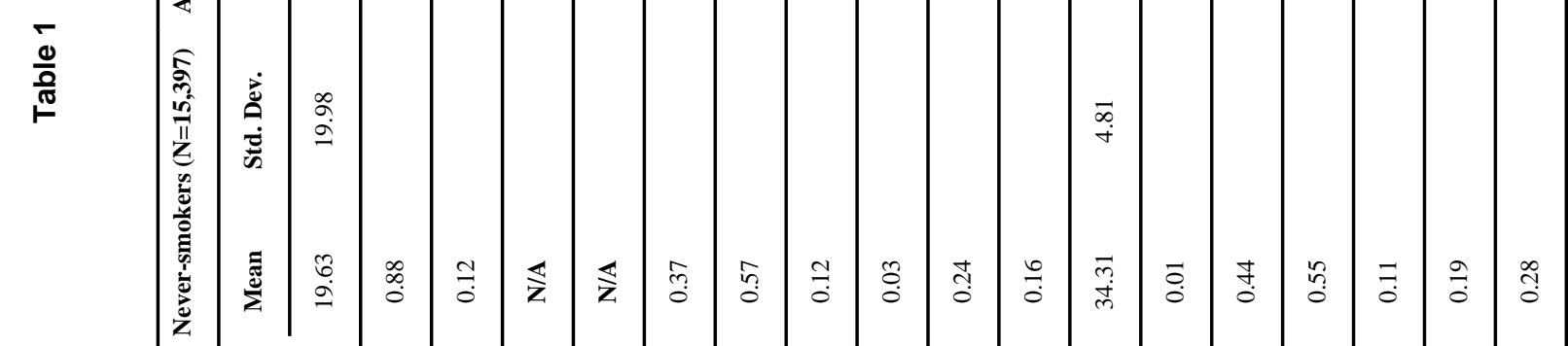

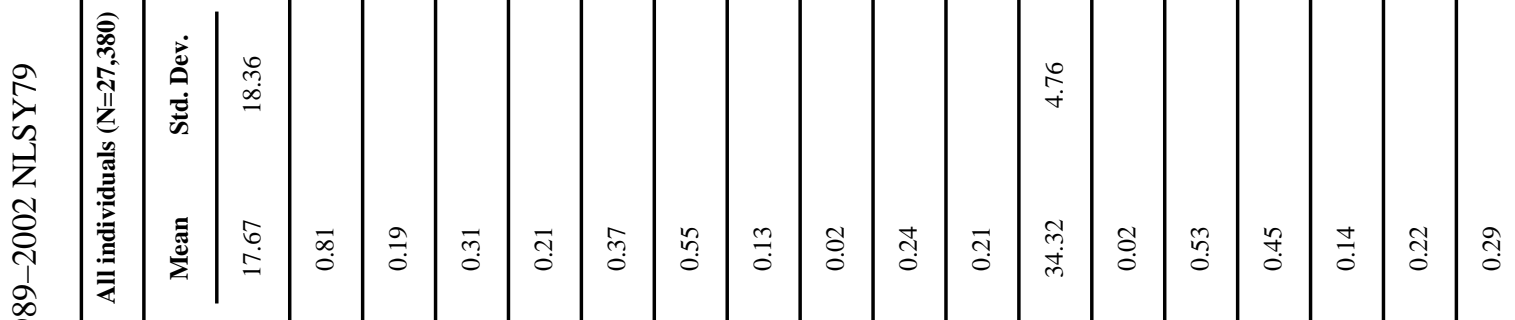




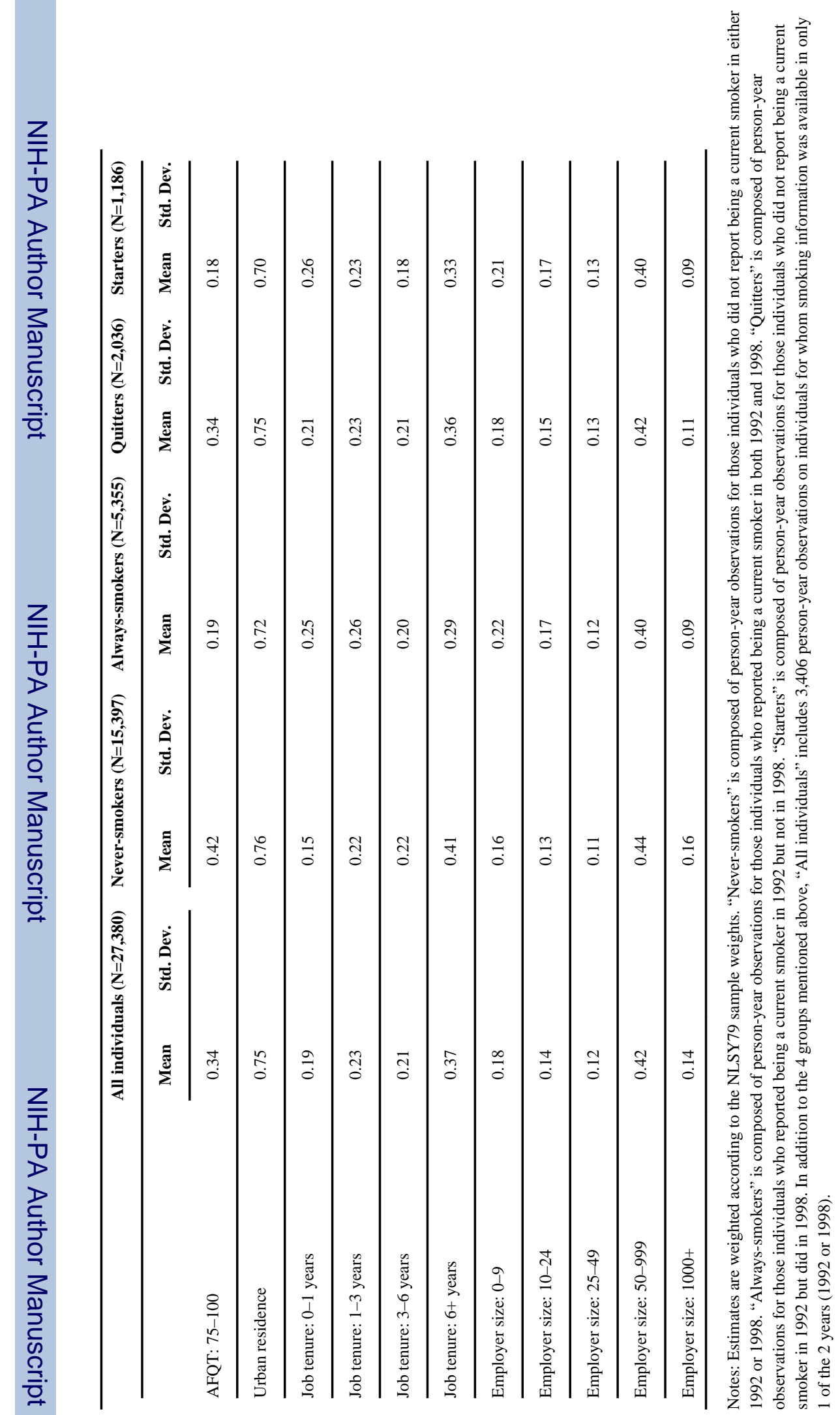




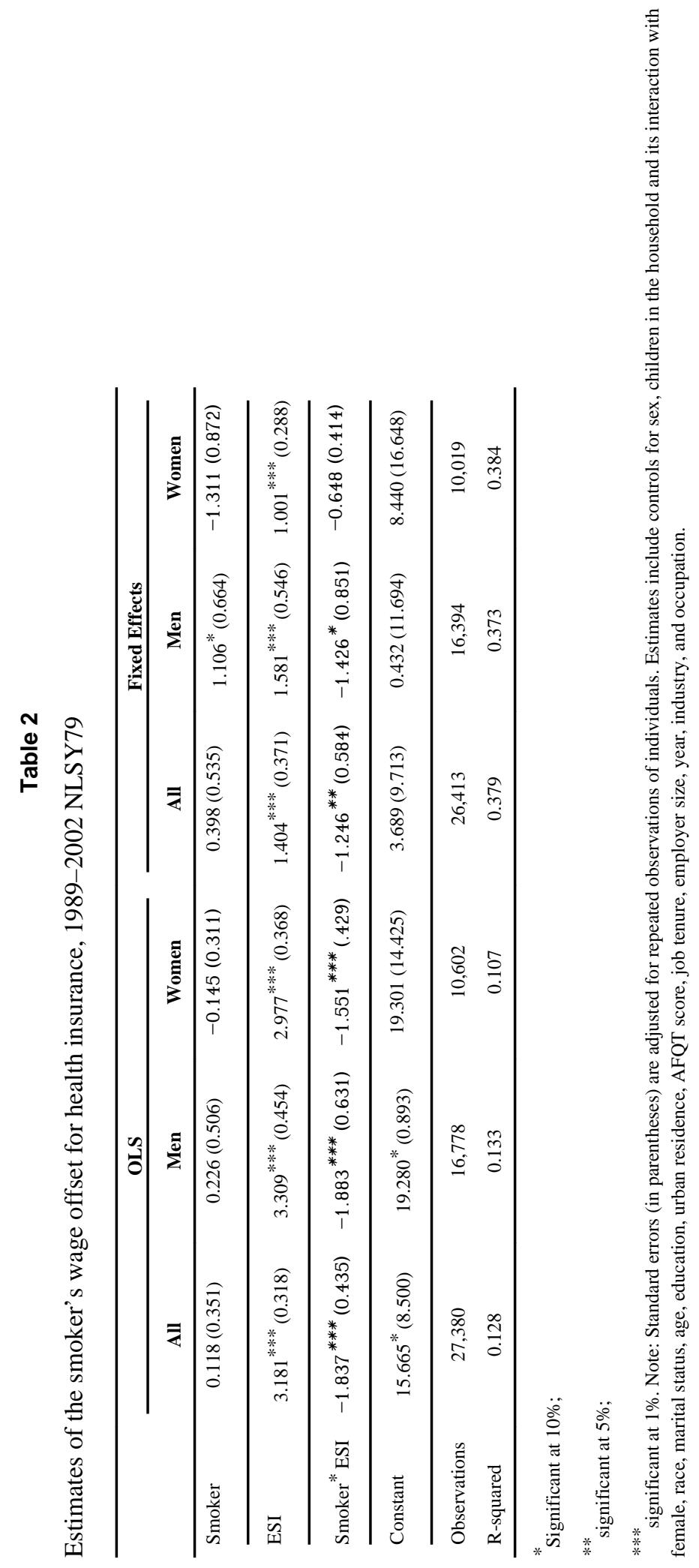


Table 3

Estimates of the smoker's wage offset for health insurance, 2000-2005 MEPS

\begin{tabular}{lccc}
\hline & & \multicolumn{2}{c}{ Coverage At Any Point During the Year } \\
\cline { 3 - 4 } & Continuously Covered by ESI or Uninsured & Offered & Held \\
\hline All & $-1.387^{* * *}(0.245)$ & $-1.516^{* * *}(0.272)$ & $-1.360^{* * *}(0.244)$ \\
\hline Women & $-1.105^{* * *}(0.360)$ & $-1.299^{* * *}(0.398)$ & $-1.082^{* * *}(0.358)$ \\
\hline Men & $-1.663^{* * *}(0.322)$ & $-1.715^{* * *}(0.353)$ & $-1.632^{* * *}(0.321)$ \\
\hline Observations (full sample) & 25,688 & 27,466 & 26,127 \\
\hline$*$ & & & \\
Significant at 10\%; & & & \\
$* *$ \\
significant at 5\%; \\
$* * *$ \\
significant at 1\%.
\end{tabular}

Note: Estimates in the table are the coefficient and standard error on the smoking and insurance coverage interaction term from different models, with each model representing a different definition of employer-sponsored insurance (see column headings). Standard errors (in parentheses) are adjusted for repeated observations of individuals. The dependent variable in all models is the worker's average hourly wage. All models include controls for the main effects of smoking and health insurance status as well as sex (when data are pooled by sex), indicator of children in the household, race, marital status, age, education, urban residence, region, employer size, year, industry, and occupation. 
Table 4

Estimates of the smoker's wage offset for health insurance by age and firm size, 1989-2002 NLSY79

\begin{tabular}{|c|c|c|c|c|}
\hline & Under age 40 & Age 40 and up & Small firms (0-49) & Large firms $(50+)$ \\
\hline Smoker & $0.001(0.385)$ & $0.706(0.588)$ & $0.224(0.453)$ & $-0.198(0.504)$ \\
\hline ESI & $3.004^{* * *}(0.350)$ & $4.279^{* * *}(0.570)$ & $3.611^{* * *}(0.393)$ & $2.748^{* * *}(0.545)$ \\
\hline Smoker ${ }^{*}$ ESI & $-1.516^{* * *}(0.472)$ & $-3.389^{* * *}(0.837)$ & $-2.225^{* * *}(0.619)$ & $-1.273^{* *}(0.595)$ \\
\hline Constant & $11.915(10.536)$ & $162.441(212.125)$ & $27.093^{*}(15.819)$ & $9.707(10.278)$ \\
\hline Observations & 23,590 & 3,790 & 11,875 & 15,505 \\
\hline R-squared & 0.109 & 0.241 & 0.105 & 0.142 \\
\hline
\end{tabular}

Note: Standard errors (in parentheses) are adjusted for repeated observations of individuals. Estimates include controls for sex, children in the household and its interaction with female, race, marital status, age, education, urban residence, AFQT score, job tenure, employer size, year, industry, and occupation. 


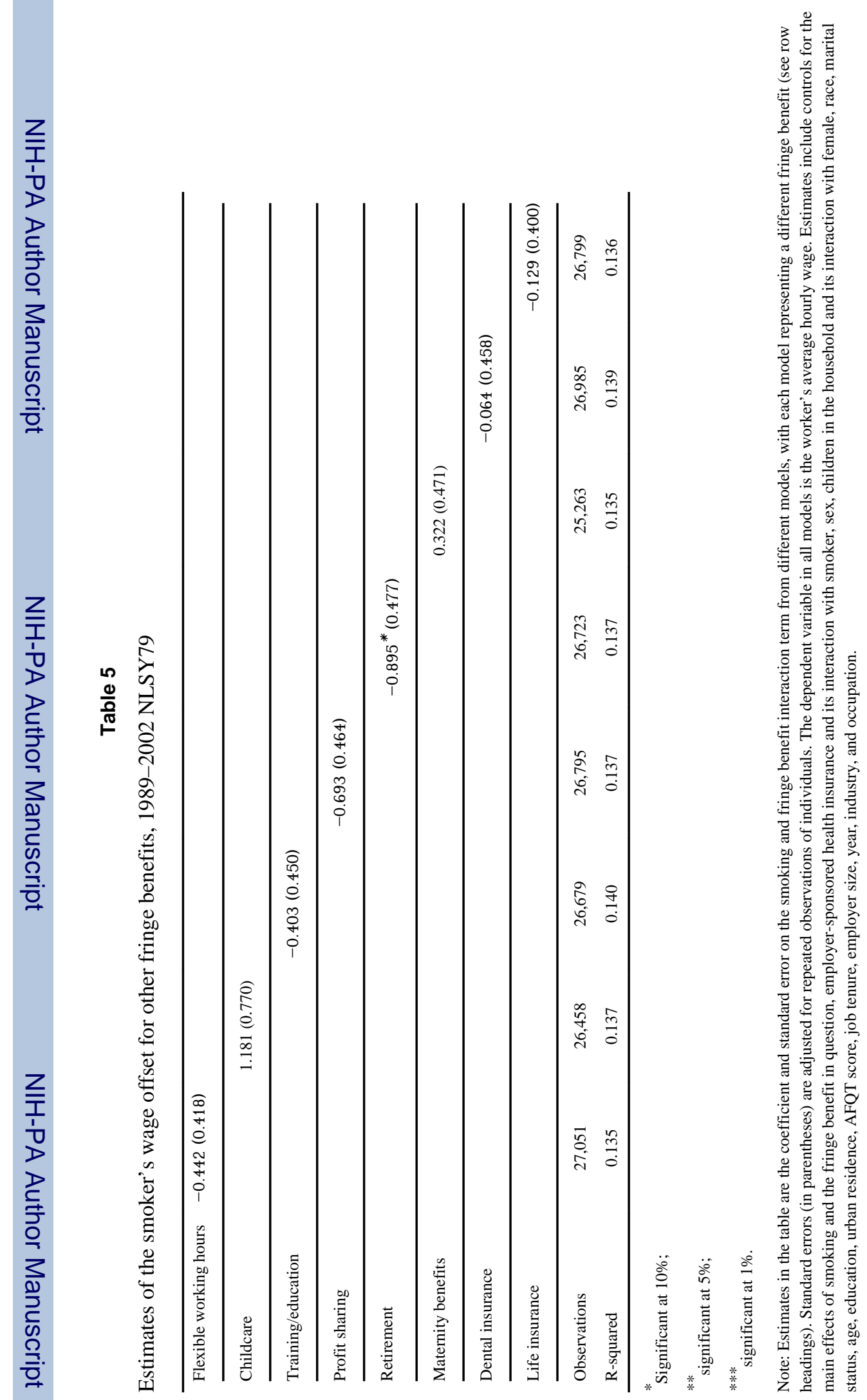


Table 6

Estimates of annual medical expenditures by smoking status and age, 2000-2005 MEPS-NHIS linked sample

\begin{tabular}{|c|c|c|c|c|}
\hline & Ever-smokers & Never-smokers & Difference & P-value assoc. $w /$ diff. \\
\hline \multicolumn{5}{|l|}{ Women } \\
\hline $18-64(\mathrm{~N}=25,142)$ & $\$ 3,424$ & $\$ 2,873$ & $\$ 551$ & 0.000 \\
\hline $18-40(\mathrm{~N}=12,359)$ & $\$ 2,301$ & $\$ 2,186$ & $\$ 115$ & 0.242 \\
\hline $41-64(\mathrm{~N}=12,783)$ & $\$ 4,262$ & $\$ 3,639$ & $\$ 623$ & 0.001 \\
\hline $20-50(\mathrm{~N}=18,345)$ & $\$ 2,702$ & $\$ 2,320$ & $\$ 383$ & 0.000 \\
\hline $20-50$ Privately insured $(\mathrm{N}=11,803)$ & $\$ 2,648$ & $\$ 2,396$ & $\$ 251$ & 0.018 \\
\hline \multicolumn{5}{|l|}{ Men } \\
\hline $18-64(\mathrm{~N}=17,679)$ & $\$ 2,280$ & $\$ 1,651$ & $\$ 628$ & 0.000 \\
\hline $18-40(\mathrm{~N}=8,850)$ & $\$ 1,225$ & $\$ 1,017$ & $\$ 208$ & 0.082 \\
\hline $41-64(\mathrm{~N}=8,829)$ & $\$ 3,114$ & $\$ 2,523$ & $\$ 591$ & 0.004 \\
\hline $20-50(\mathrm{~N}=13,470)$ & $\$ 1,730$ & $\$ 1,298$ & $\$ 433$ & 0.002 \\
\hline $20-50$ Privately insured $(\mathrm{N}=9,398)$ & $\$ 1,649$ & $\$ 1,368$ & $\$ 281$ & 0.086 \\
\hline \multicolumn{5}{|l|}{ Combined } \\
\hline $18-64(\mathrm{~N}=42,821)$ & $\$ 2,854$ & $\$ 2,374$ & $\$ 481$ & 0.000 \\
\hline $18-40(\mathrm{~N}=21,209)$ & $\$ 1,757$ & $\$ 1,682$ & $\$ 75$ & 0.361 \\
\hline $41-64(\mathrm{~N}=21,612)$ & $\$ 3,698$ & $\$ 3,214$ & $\$ 484$ & 0.001 \\
\hline $20-50(\mathrm{~N}=31,815)$ & $\$ 2,211$ & $\$ 1,878$ & $\$ 332$ & 0.000 \\
\hline $20-50$ Privately insured $(\mathrm{N}=21,201)$ & $\$ 2,142$ & $\$ 1,942$ & $\$ 200$ & 0.047 \\
\hline
\end{tabular}

Note: Estimates are weighted means. Individuals receiving insurance through the Veterans' Administration or Workers' Compensation programs are excluded. 


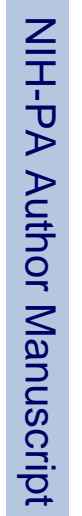

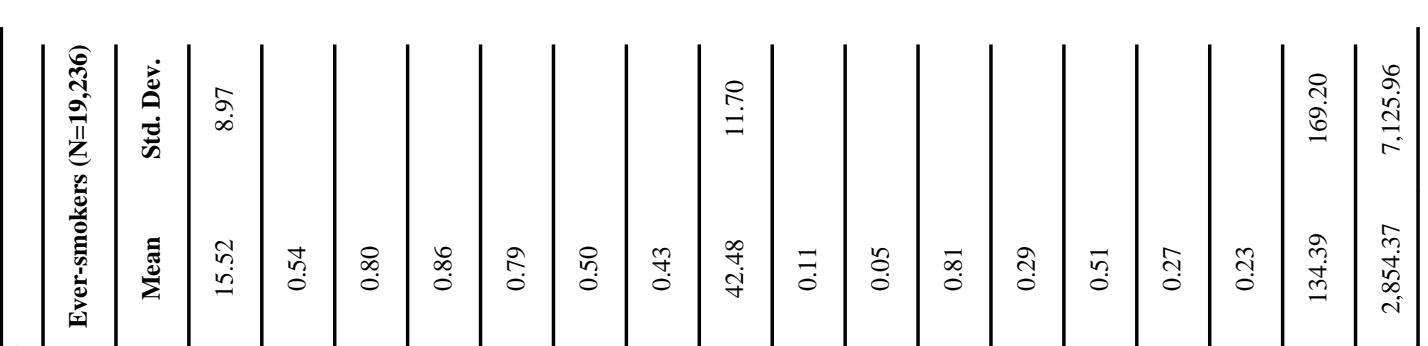

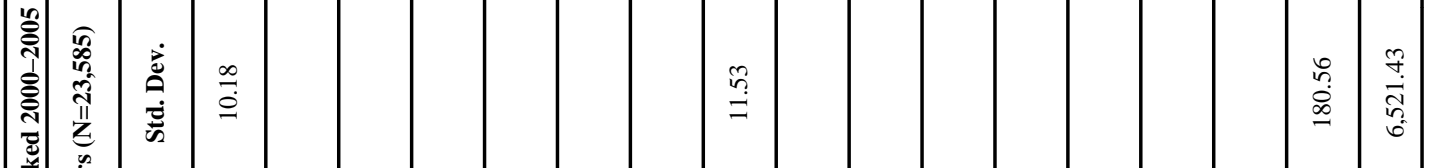

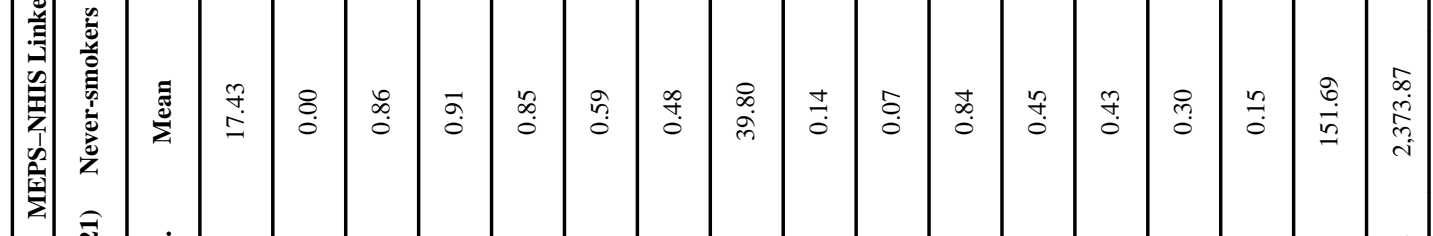

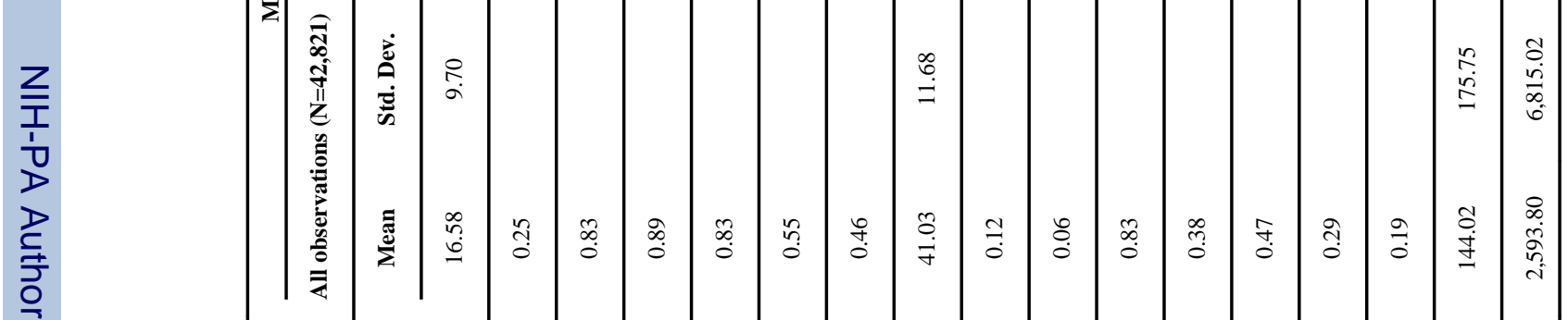

$\frac{2}{\frac{2}{2}}$

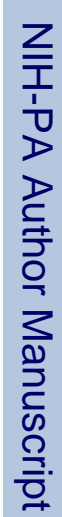

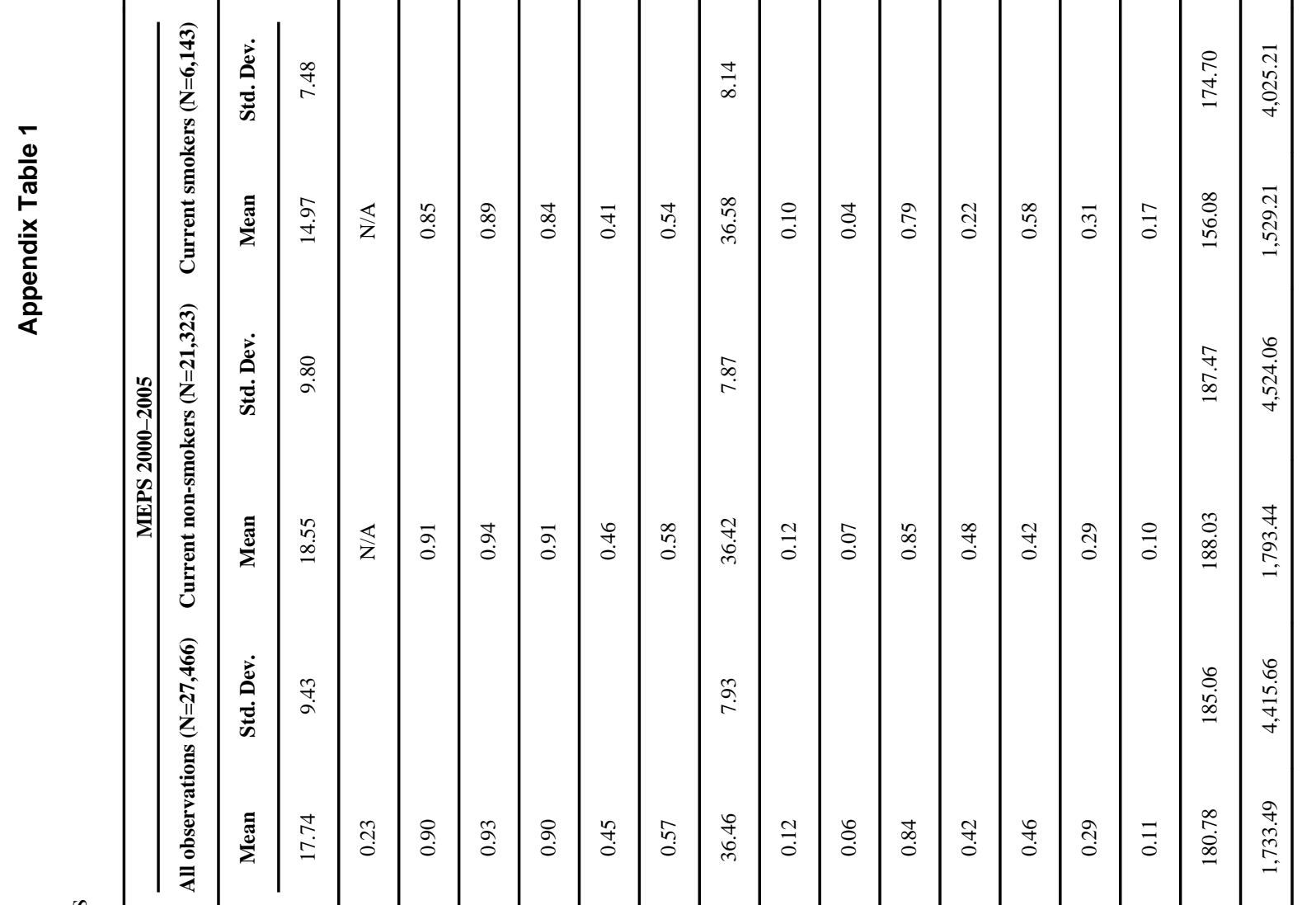

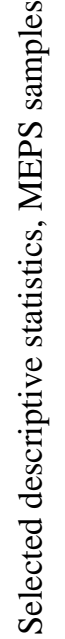

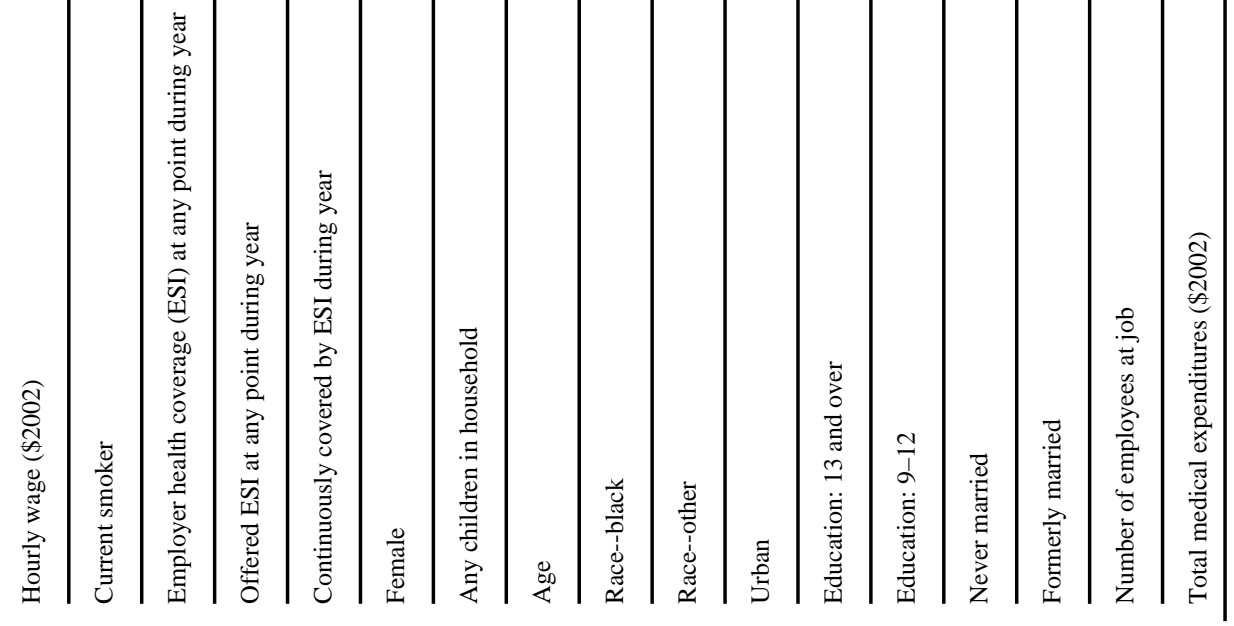




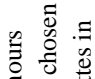
证

$z \stackrel{0}{\frac{D}{\omega}}$

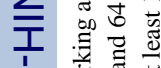

T)

$\geq$ 空嵒

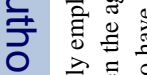

了

空

क

유.

娄产

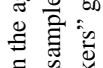

离号

$\boldsymbol{Z}$

至

T

又

은 它 을

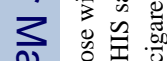

כ)

क

움 镸

.듕

要要

可

ज क

王

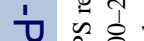

$>\sum$ 舟

空

은

उ जे

ट

음

원

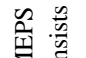

$\sum^{2}$

悹

寻表

要拕

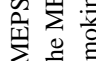

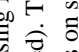

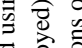

递

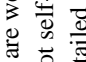

造

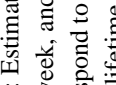

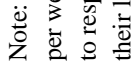

$J$ Health Econ. Author manuscript; available in PMC 2012 September 1. 


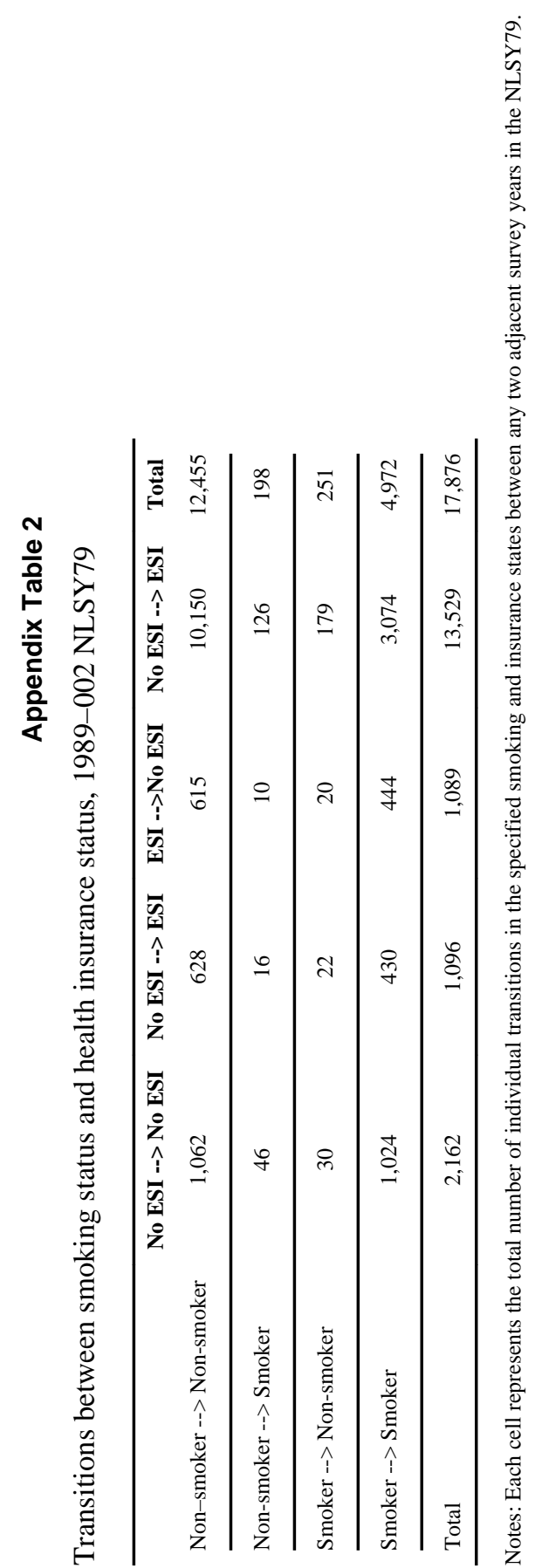

